\title{
Effect of Cobalt Powder Morphology on the Properties of WC-Co Hard Alloys
}

\author{
A. S. Kurlov ${ }^{a}$ and A. A. Rempel ${ }^{a, b}$ \\ ${ }^{a}$ Institute of Solid State Chemistry, Ural Branch, Russian Academy of Sciences, \\ Pervomaiskaya ul. 91, Yekaterinburg, 620990 Russia \\ ${ }^{b}$ Yeltsin Federal University, ul. Mira 19, Yekaterinburg, 620002 Russia \\ e-mail:kurlov@ihim.uran.ru \\ Received February 6, 2013
}

\begin{abstract}
The effect of cobalt powder morphology on the microstructure of WC-Co hard alloys produced by sintering cobalt + tungsten carbide powder mixtures has been studied using X-ray diffraction, laser diffraction, scanning electron microscopy, density measurements, and Vickers microhardness tests. The results indicate that, under identical sintering conditions, the densest and most homogeneous microstructure is formed in hard alloys sintered using cobalt powders consisting of rounded particles. The use of cobalt powders with dendritic morphologies impedes the homogenization of $\mathrm{Co}+\mathrm{WC}$ powder mixtures and preparation of pore-free WC-Co hard alloys.
\end{abstract}

DOI: $10.1134 / \mathrm{S} 0020168513080086$

\section{INTRODUCTION}

There are currently a diversity of WC-Co alloys, which differ in cobalt content, carbide particle size, the presence of various reinforcing and inhibiting additives, etc. Such alloys always contain two components: tungsten carbide, WC, which acts as a "hard phase," and cobalt, Co, which is used as a binder. A combination of the excellent mechanical properties of tungsten carbide and the plasticity and high fracture toughness of cobalt ensures high hardness, strength, and wear resistance of WC-Co hard alloys. Owing to this, they are widely used as tool materials in the metal-working and mining industries.

The most promising approach to improving the performance of $\mathrm{WC}-\mathrm{Co}$ hard alloys is to produce finegrained microstructures or even nanostructures in the alloys. This requires the use of fine-grained and nanocrystalline powders of both tungsten carbide and cobalt and special sintering procedures [1-7].

Given the above, the purpose of this research is to analyze the effect of the particle size and morphology of starting cobalt powders on the properties of $\mathrm{WC}-\mathrm{Co}$ alloys containing 6 to $10 \mathrm{wt} \%$ cobalt.

\section{EXPERIMENTAL}

Samples of WC-Co hard alloys were prepared using $\mathrm{Co}($ th08) and $\mathrm{Co}$ (th14) cobalt powders with an average particle size of 0.8 and $1.4 \mu \mathrm{m}$, respectively, produced thermochemically, and electrolytic cobalt powder, $\mathrm{Co}(\mathrm{el})$. These cobalt powders were manufactured at the Electrochemical Converter Plant (ECP), OAO Ural
Electrochemical Integrated Plant (UEIP). For comparison, we used Co(kzts) microcrystalline cobalt powder with an average particle size of $2.2 \mu \mathrm{m}$, manufactured at the Kirovgrad Hard Alloys Plant (OAO KZTS, Kirovgrad, Sverdlovsk oblast, Russia). The basic component in the fabrication of the hard alloys was microcrystalline tungsten carbide (WC) powder with an average particle size of $7.6 \mu \mathrm{m}$, manufactured at $\mathrm{OAO}$ KZTS for the fabrication of microcrystalline hard alloys.

All of the cobalt and tungsten carbide powders were characterized by X-ray diffraction, laser diffraction, scanning electron microscopy, mass spectrometry, and chemical analysis.

The starting WC powder was analyzed for total carbon $\left(\mathrm{C}_{\text {total }}\right)$ and free carbon $\left(\mathrm{C}_{\text {free }}\right)$ on a Metavak CS-30 carbon/sulfur analyzer. The WC powder was found to contain $6.06 \mathrm{wt} \% \mathrm{C}_{\text {total }}$ and $0.20 \mathrm{wt} \% \mathrm{C}_{\text {free }}$. Spectral analyses of the cobalt and tungsten carbide powders were carried out on a PerkinElmer SCIEX ELAN 9000 mass spectrometer. The results indicated that the total content of impurity elements in the powders was within $0.01 \mathrm{wt} \%$. One exception was the Co(el) powder, which contained $0.03 \mathrm{wt} \%$ chromium and $0.35 \mathrm{wt} \%$ iron, and the other exception was the Co(th08) powder, which contained $0.01 \mathrm{wt} \%$ magnesium and $0.09 \mathrm{wt} \%$ nickel.

The phase composition of the starting powders was determined by $\mathrm{X}$-ray diffraction in the angular range $2 \theta=10^{\circ}-140^{\circ}$ on a Shimadzu XRD-7000 diffractometer with $\mathrm{Cu} K_{\alpha_{1,2}}$ radiation.

The particle size distributions of the Co and WC starting powders were assessed with a Horiba Partica 


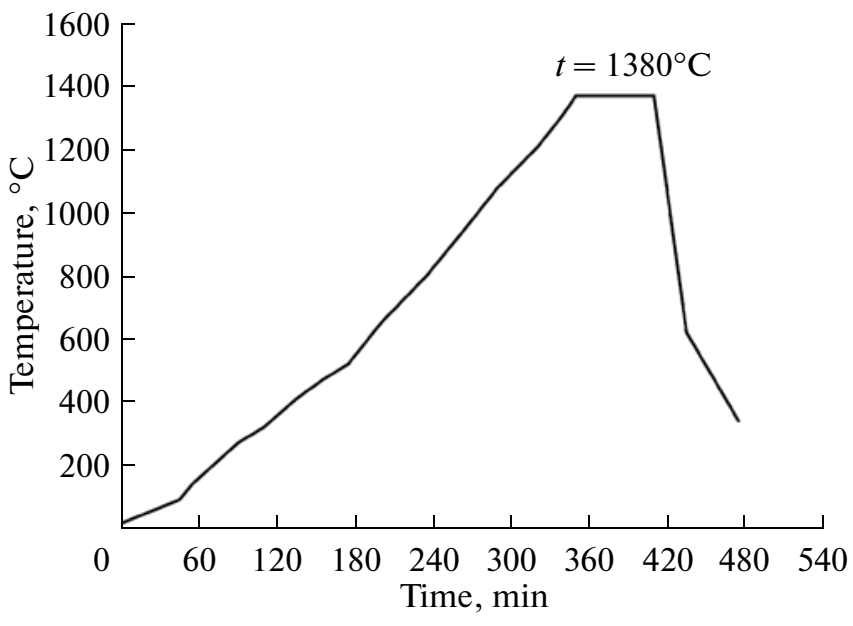

Fig. 1. Temperature profile used to sinter the VK6, VK8, and VK10 hard alloys.

LA-950V2 laser diffraction particle size analyzer using two laser light sources, with wavelengths of 650 and $405 \mathrm{~nm}$.

In addition, the cobalt and tungsten carbide starting powders and sintered WC-Co hard alloys were examined by scanning electron microscopy (SEM) on a JEOL JSM-6390 LA electron microscope.

Homogeneous VK6 (WC + 6 wt \% Co), VK8 (WC + $8 \mathrm{wt} \% \mathrm{Co}$ ), and $\mathrm{VK} 10(\mathrm{WC}+10 \mathrm{wt} \% \mathrm{Co}$ ) powder mixtures were prepared by grinding tungsten carbide (WC) with one of the cobalt powders (Co(th08), Co(th14), $\mathrm{Co}(\mathrm{el})$, or Co(kzts)) in a Retsch PM 200 planetary ball mill. The process was run in isopropanol for $30 \mathrm{~min}$ at a vial rotation rate of $300 \mathrm{rpm}$ and a ball-to-powder weight ratio of $2: 1$. After mixing, the powders were dried for several hours. Next, the powder mixtures were thoroughly mixed with a plasticizer (rubber solution in benzine) until complete wetting. The resultant mixtures were dried and passed through a fine sieve with an aperture size of $125 \mu \mathrm{m}$ ( $120 \mathrm{mesh}$ ). The mixtures thus prepared were compacted by uniaxial compression at a pressure of $950 \mathrm{MPa}$ into pellets $7.5 \mathrm{~mm}$ in diameter and $8.0 \mathrm{~mm}$ in thickness. The pellets were sintered in an $\mathrm{SShV}-1.2 .5 / 25 \mathrm{I} 1$ vacuum furnace in a vacuum on the order of $10^{-2} \mathrm{~Pa}$ under the temperature profile shown in Fig. 1.

The phase composition of the hard alloys was determined by $\mathrm{X}$-ray diffraction in the angular range $2 \theta=30^{\circ}-80^{\circ}$ with a scan step $\Delta(2 \theta)=0.03^{\circ}$ on a DRON-UM1 automatic diffractometer (BraggBrentano geometry, $\mathrm{Cu} K_{\alpha_{1,2}}$ radiation).

The density of the sintered samples of the hard alloys was determined by hydrostatic weighing. The porosity of the samples was evaluated by comparing their measured and theoretical densities.
Polished sections of the sintered samples of the hard alloys for microstructural examination and microhardness measurements were prepared using a Buehler integrated metallographic system which included a PNEUMET-II specimen mounting press, MOTOPOL-8 grinder/polisher, and MICROMET-1 microhardness tester. The sections were ground and polished to a mirror finish with 30 - to $1-\mu \mathrm{m}$ diamond slurries. Microhardness was determined on polished sections with a Vickers diamond indenter on the MICROMET- 1 in automatic mode. The indentation load was $1 \mathrm{~N}$, and the dwell time was $10 \mathrm{~s}$.

\section{RESULTS AND DISCUSSION}

$\mathrm{X}$-ray diffraction characterization showed that the tungsten carbide powder contained, in addition to the major phase $\mathrm{WC}$, the lower tungsten carbide $\mathrm{W}_{2} \mathrm{C}$ (about 2 wt \%). The four cobalt powders consisted of roughly equal percentages of the low-temperature phase $\alpha$-Co (hexagonal close-packed structure) and the high-temperature phase $\beta$-Co (face-centered cubic structure).

According to SEM results, all of the powders were microcrystalline and consisted of particles ranging in size from 1 to $10 \mu \mathrm{m}$. The Co(th08), Co(th14), and Co(kzts) cobalt powders were very similar in morphology. The particles in these powders ranged in size from $300 \mathrm{~nm}$ to $5 \mu \mathrm{m}$ and had the form of intergrowths of finer particles (Fig. 2). The Co(el) powder had a different morphology: at a magnification of $1500 \times$, its particles were seen to be 2 to $5 \mu \mathrm{m}$ in length and about $1 \mu \mathrm{m}$ in thickness and to form a branched dendritic structure (Fig. 3a). At a magnification of $7000 \times$, elongated large particles were seen to be intergrowths of roughly isometric $(\sim 1 \mu \mathrm{m})$ particles (Fig. 3b). The WC powder consisted of rounded aggregated particles with an average size of about $6 \mu \mathrm{m}$, made up of fine particles $100 \mathrm{~nm}$ or more in size (Fig. 4).

The particle size distributions obtained using laser diffraction showed that the powders ranged widely in particle size (Table 1). According to the laser diffraction data, the average particle size $\bar{D}$ of the powders was 8 to $20 \mu \mathrm{m}$, slightly exceeding that obtained by SEM. This points to significant particle agglomeration in the powders.

The morphology, crystal-chemical characteristics, and particle sizes of the cobalt powders used in this study were described in detail previously [8].

Samples of the VK6, VK8, and VK10 hard alloys containing one of the cobalt powders (Co(th08), $\mathrm{Co}(\mathrm{th} 14), \mathrm{Co}(\mathrm{el})$, or $\mathrm{Co}(\mathrm{kzts}))$ as a binder were sintered in vacuum using the same temperature profile (Fig. 1).

SEM examination of polished sections of the sintered hard alloys showed that, according to the grain size of the solid phase, all of the samples of the hard alloys were microcrystalline and had a rather homoge- 

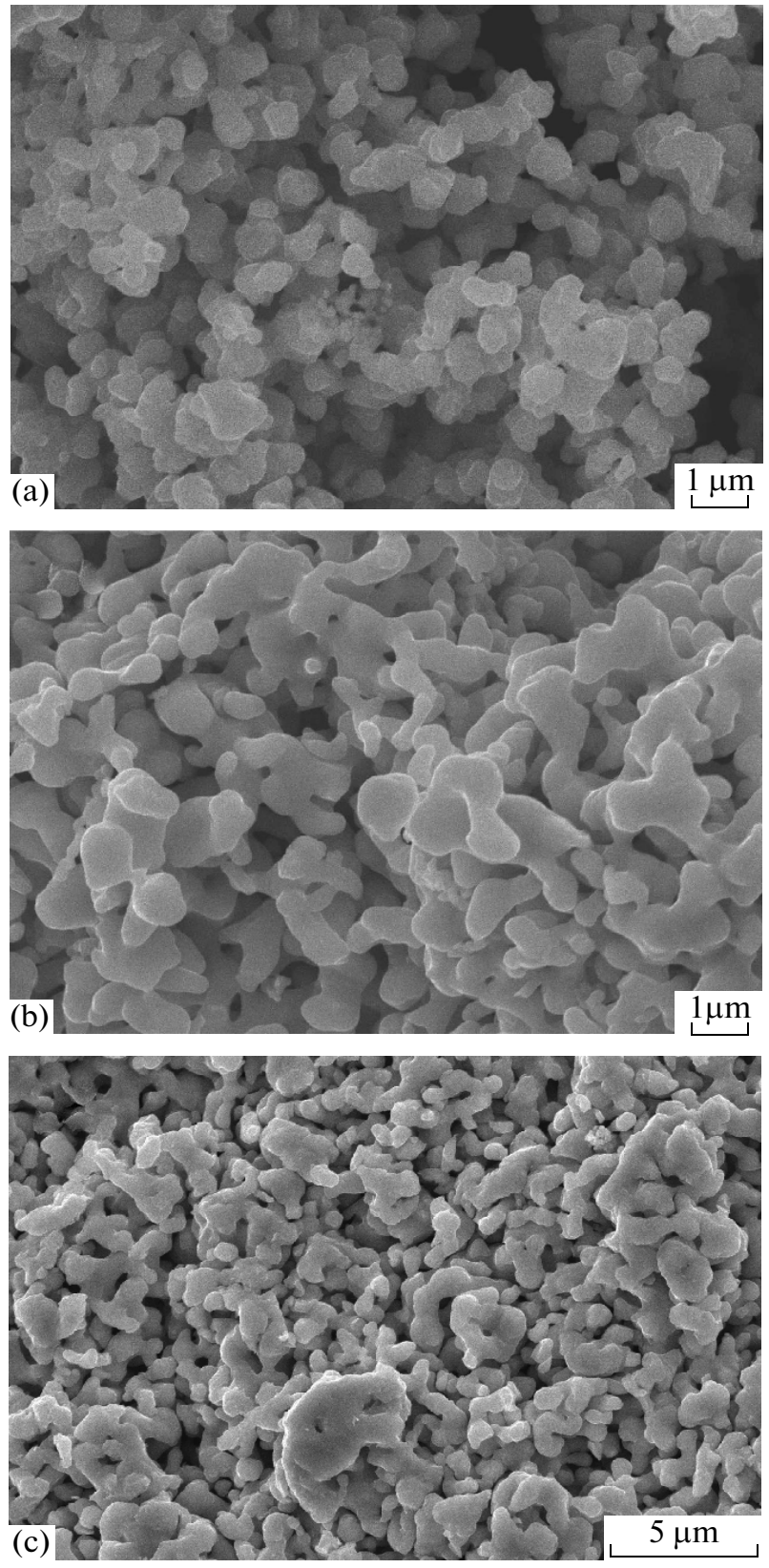

Fig. 2. SEM images of the cobalt powders: $(a, b) \mathrm{Co}(\mathrm{th} 08)$ and $\mathrm{Co}(\mathrm{th} 14)$ thermochemically prepared powders at a magnification of $10000 \times$, (c) $\mathrm{Co}(\mathrm{kzts})$ powder at a magnification of $5000 \times$. neous, dense microstructure, except for the hard alloys that were produced using the electrolytic cobalt powder $\mathrm{Co}(\mathrm{el})$ as a binder. As an example, Fig. 5 shows micrographs of polished sections of the VK6 hard alloys prepared using different cobalt powders. It is well seen that the surface layer of the VK6 hard alloys sintered using the $\mathrm{Co}$ (th08), $\mathrm{Co}$ (th14), and $\mathrm{Co}$ (kzts) powders is almost free of pores. The size of the observed individual pores does not exceed 1-2 $\mu \mathrm{m}$. In contrast, the hard alloy sintered using the Co(el) powder has appreciable porosity, with individual pores ranging in size up to $10 \mu \mathrm{m}$ (Fig. 5d). The SEM data are well consistent with the measured densities and porosities: the hard alloys produced using the $\mathrm{Co}(\mathrm{el})$ powder have the lowest density and the highest porosity (Table 2).

On the whole, the highest density and hardness were offered by the samples of the WC-Co hard alloys fabricated using the Co(th14) powder. The alloys produced using the Co(th08) cobalt powder had a slightly lower hardness (Table 2).

Among the hard alloys prepared using the $\mathrm{Co}$ (kzts) powder, only the VK8 samples were slightly inferior in hardness to the analogous hard alloys produced using the $\mathrm{Co}(\mathrm{th} 14)$ and $\mathrm{Co}(\mathrm{th} 08)$ cobalt powders.

Energy dispersive X-ray microanalysis of the surface of the hard alloys showed that the cobalt binder was uniformly distributed over the carbide grains, indicating good densification and sinterability of the starting tungsten carbide (WC) and thermochemically prepared Co powders. The presence of large pores in the VK6 hard alloy containing the electrolytic cobalt powder Co(el) (Fig. 5d) points to poor morphological compatibility between the WC and Co(el) starting powders. Judging from the pore size data, it is reasonable to assume that the sintering process involved the melting of the large dendritic particles of the starting Co(el) powder and that the resulting cobalt melt redistributed through the tungsten carbide grain boundaries. As a result of the melting of a large dendritic $\mathrm{Co}(\mathrm{el})$ particle, the space occupied by it in the solid state in the sample became free and remained so in the sintering process. As a result, large pores formed. Thus, the use of the cobalt powder with a dendritic microstructure led to the formation of a porous hard alloy. By contrast, under the
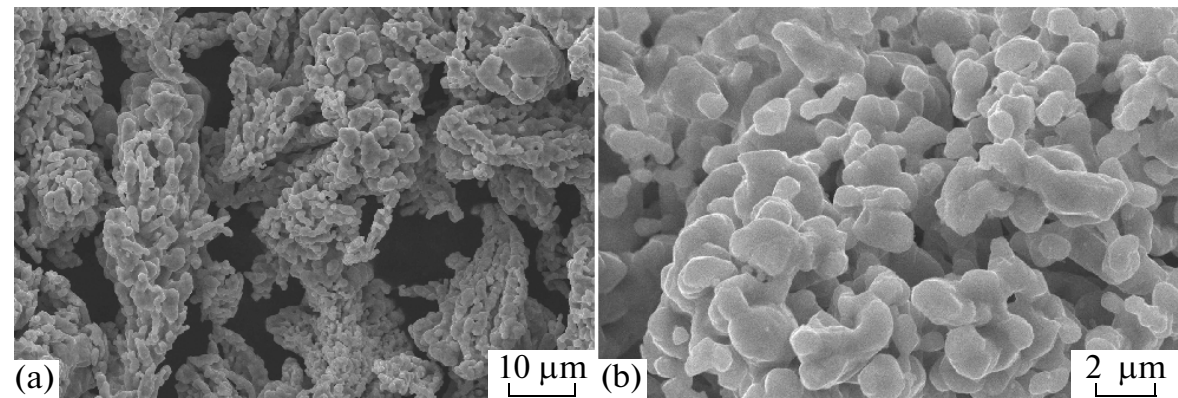

Fig. 3. SEM images of the electrolytically prepared cobalt powder, Co(el): (a) magnification of $1500 \times$, (b) magnification of $7000 \times$. 


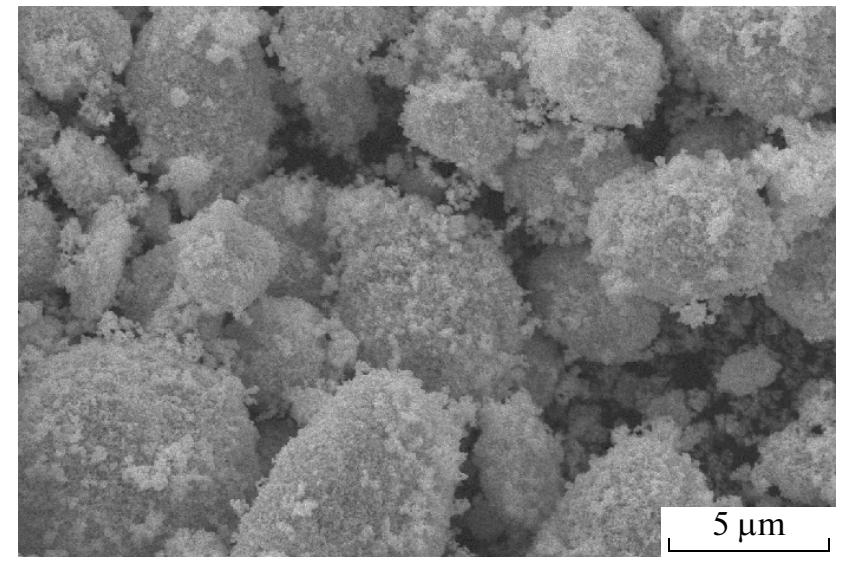

Fig. 4. SEM image of the WC powder at a magnification of $5000 \times$.
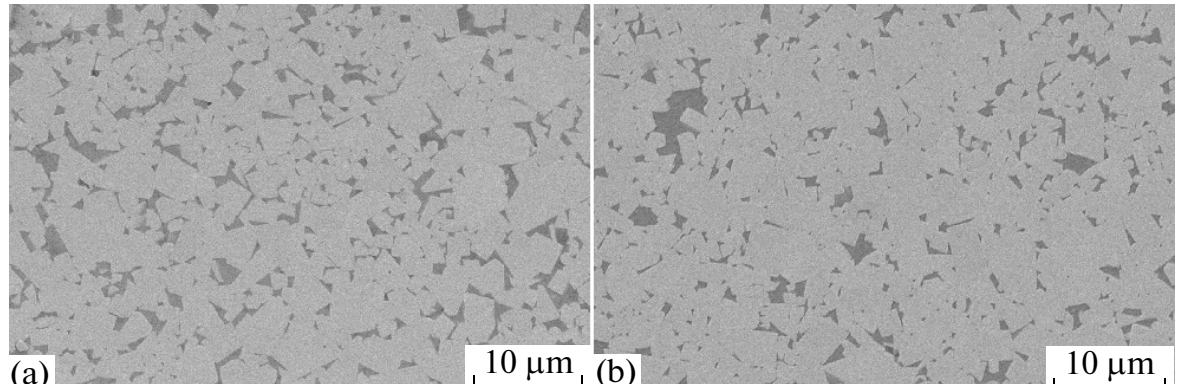

(a) (b)
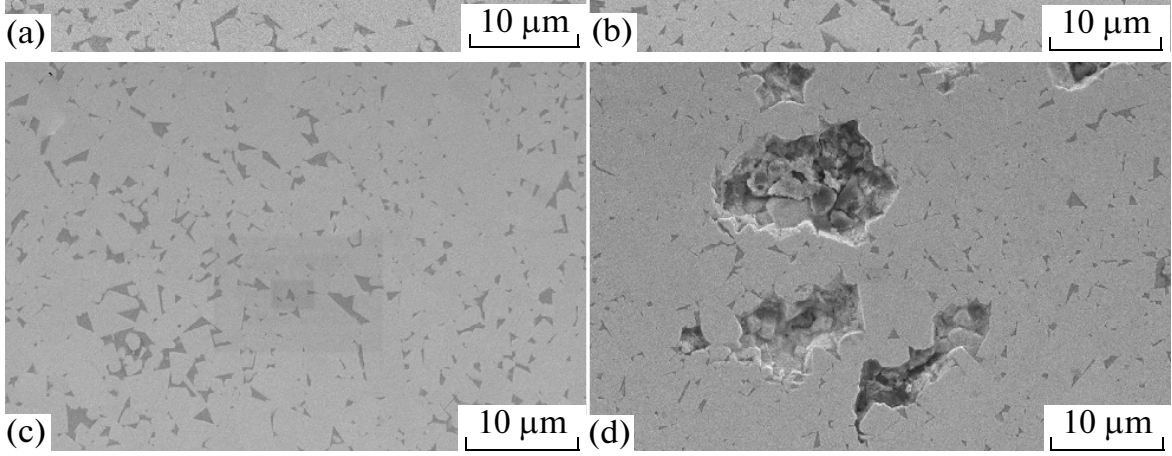

Fig. 5. SEM images of polished sections of VK6 alloys prepared using different cobalt powders (magnification of $2500 \times$ ): (a) Co(th08), (b) $\mathrm{Co}($ th14), (c) $\mathrm{Co}(\mathrm{kzts})$, (d) $\mathrm{Co}(\mathrm{el})$.

Table 1. Particle size of the starting powders according to laser diffraction data

\begin{tabular}{l|c|c|c|c|c}
\hline \multicolumn{1}{c|}{ Powder } & $\bar{D}, \mu \mathrm{m}$ & $D_{\min }, \mu \mathrm{m}$ & $D_{\max }, \mu \mathrm{m}$ & $D(50 \%), \mu \mathrm{m}$ & $D(95 \%), \mu \mathrm{m}$ \\
\hline Co(th08) & 8.5 & 3.0 & 20.0 & 8.0 & 14.0 \\
Co(th14) & 18.5 & 2.0 & 90.0 & 15.0 & 45.0 \\
Co(el) & 19.2 & 4.0 & 50.0 & 18.0 & 30.0 \\
Co(kzts) & 13.0 & 1.5 & 100.0 & 10.0 & 40.0 \\
WC & 5.8 & 0.8 & 17.0 & 5.5 & 11.0 \\
\hline
\end{tabular}

Note: $D(50 \%)$ is the median particle size (50\% of the particles have a size $D \leq D(50 \%)$ ), and $D(95 \%)$ is the particle size such that $95 \%$ of the particles have a size $D \leq D(95 \%)$. 
Table 2. Density $\rho$, porosity $\Pi$, and microhardness $H_{\mathrm{V}}$ of WC-Co hard alloys produced using different cobalt powders

\begin{tabular}{l|l|c|c|c}
\hline $\begin{array}{c}\text { Hard } \\
\text { alloy }\end{array}$ & $\begin{array}{c}\text { Cobalt } \\
\text { powder }\end{array}$ & $\begin{array}{c}\rho \pm 0.04, \\
\mathrm{~g} / \mathrm{cm}^{3}\end{array}$ & $\Pi \pm 0.1, \%$ & $\begin{array}{c}H_{\mathrm{V}} \pm 0.5, \\
\mathrm{GPa}\end{array}$ \\
\hline VK6 & Co(th08) & 14.98 & 0.1 & 17 \\
VK6 & Co(th14) & 14.97 & 0.1 & 18 \\
VK6 & Co(el) & 14.48 & 3.4 & 16 \\
VK6 & Co(kzts) & 15.03 & 0 & 17 \\
VK8 & Co(th08) & 14.69 & 0.5 & 16 \\
VK8 & Co(th14) & 14.80 & 0 & 16 \\
VK8 & Co(el) & 14.58 & 1.3 & 16 \\
VK8 & Co(kzts) & 14.72 & 0.3 & 15 \\
VK10 & Co(th08) & 14.57 & 0 & 14 \\
VK10 & Co(th14) & 14.62 & 0 & 16 \\
VK10 & Co(el) & 14.62 & 0 & 16 \\
VK10 & Co(kzts) & 14.59 & 0 & 14 \\
\hline
\end{tabular}

same sintering conditions the use of the Co(th08), $\mathrm{Co}(\mathrm{th} 14)$, and $\mathrm{Co}(\mathrm{kzts})$ cobalt powders, in which the particles were not intergrown and were rounded in shape, led to the formation of dense, homogeneous hard alloys.

\section{CONCLUSIONS}

The morphology of cobalt powders used as binders influences the microstructure of sintered $\mathrm{WC}-\mathrm{Co}$ hard alloys. In producing hard alloys, it is best to employ cobalt powders in which the particles are not intergrown and are rounded in shape (almost spherical). Dendritic morphologies of cobalt powders impede the homogenization and compaction of WC + Co powder mixtures, so that pore-free hard alloys are difficult to produce from such mixtures.

\section{ACKNOWLEDGMENTS}

This work was supported by the Ural Branch and Presidium of the Russian Academy of Sciences, project no. 12-P-234-2003, program no. 24: Fundamental Issues in Technologies of Nanostructures and Nanomaterials.

\section{REFERENCES}

1. Klyachko, L.I., Fal'kovskii, V.A., and Khokhlov, A.M., Tverdye splavy na osnove karbida vol'frama s tonkodispersnoi strukturoi (Fine-Grained Tungsten Carbide Based Hard Alloys), Moscow: Ruda i Metally, 1999.

2. Fang Z. Zak, Wang Xu, Ryu Taegong, et al., Synthesis, sintering, and mechanical properties of nanocrystalline cemented tungsten carbide-a review, Int. J. Refract. Met. Hard Mater., 2009, vol. 27, no. 2, pp. 288-299.

3. Kurlov, A.S., Gusev, A.I., and Rempel, A.A., Vacuum sintering of WC-8 wt \% Co hard metals from WC powders with different dispersity, Int. J. Refract. Met. Hard Mater., 2011, vol. 29, no. 2, pp. 221-231.

4. Kurlov, A.S., Leenaers, A., Berghe, S., et al., Microstructure of nanocrystalline WC powders and WC-Co hard alloys, Rev. Adv. Mater. Sci., 2011, vol. 27, no. 2, pp. 165-172.

5. Kurlov, A.S. and Gusev, A.I., Vacuum annealing of nanocrystalline WC powders, Inorg. Mater., 2012, vol. 48, no. 7, pp. 680-690.

6. Kurlov, A.S. and Gusev, A.I., Peculiarities of vacuum annealing of nanocrystalline WC powders, Int. J. Refract. Met. Hard Mater., 2012, vol. 32, no. 5, pp. 51-60.

7. Kurlov, A.S., Effect of vacuum annealing on the particle size and phase composition of nanocrystalline tungsten carbide powders, Russ. J. Phys. Chem. A, 2013, vol. 87, no. 4, pp. 654-661.

8. Kurlov, A.S., Rempel', A.A., Matrenin, V.I., and Stikhin, A.S., Morphology and crystal-chemical characteristics of cobalt and nickel nanopowders prepared by thermochemical and electrolytic methods, Inorg. Mater., 2013, vol. 49, no. 2, pp. 153-158.

Translated by $O$. Tsarev 